\title{
Izboljševanje kakovosti regulacije - razvoj v Sloveniji
}

\author{
UDK: 35:005.336.3(497.4)
}

\author{
Gregor Virant \\ Univerza v Ljubljani, Fakulteta za upravo \\ gregor.virant@fu.uni-lj.si
}

\begin{abstract}
IZVLEČEK
Programi izboljševanja kakovosti regulacije v EU so rezultat različnih procesov (procesa uvajanja upravljanja celovite kakovosti v državno upravo, težnje po izboljšanju konkurenčnosti gospodarstva, želje po približanju institucij državljanom).

Kakovost predpisov obsega več elementov: presojo učinkov, sodelovanje javnosti, sodelovanje izvajalcev, odpravo administrativnih ovir, nomotehnično, jezikovno in stilistično korektnost.

Za resničen dvig kakovosti so potrebni jasni standardi, iskrena predanost vlade temu cilju, kompetentni pripravljavci predpisov in ustrezna porazdelitev odgovornosti med predlagatelje in nadzornike. Slovenska državna uprava je na tem področju po letu 2000 naredila velike korake, med katerimi velja izpostaviti spremembe Poslovnika vlade v letu 2006. Tudi resolucija o normativni dejavnosti iz leta 2009 je korak v pravo smer.

Ostaja pa še manevrski prostor za nadgradnjo procesov izboljšave predpisov - vpeljava standarda sodelovanja izvajalcev predpisov pri njihovi pripravi, sprejem zavezujoče metodologije za doseganje posameznih elementov kakovosti regulacije, razvoj in zagon stalnega modula usposabljanja.
\end{abstract}

Ključne besede: kakovost predpisov, boljša regulacija, odprava administrativnih ovir, presoja učinkov regulacije 


\section{Gregor Virant \\ Izboljševanje kakovosti regulacije - razvoj v Sloveniji}

\section{Izboljševanje kakovosti regulacije - rezultat različnih (konvergenčnih) procesov}

Izdajanje predpisov (oblastnih splošnih pravnih aktov) ${ }^{\mathbf{1}}$ je ena temeljnih dejavnosti oblasti in eden temeljnih mehanizmov urejanja družbenih razmerij, predpisi pa eden najpomembnejših "produktov" procesov javnega upravljanja. Pri tem niso mišljeni samo zakoni, ampak tudi podzakonski predpisi, ki niso zgolj instrument uporabe prava ali interpretacije zakonov, ampak instrument oblikovanja politike in s tem urejanja družbenih razmerij.

Proces izboljševanja kakovosti predpisov je postopoma prodiral v "zavest" institucij Evropske unije in nacionalnih vlad in javnih uprav. Razmišljanje o izboljšanju kakovosti predpisov se je na agendi Evropske unije in njenih držav članic pojavilo $\vee$ 90. letih prejšnjega stoletja, ko je edinburški vrh (1992) pod britanskim predsedstvom izrazil zaskrbljenost nad kakovostjo in količino predpisov, ki prihajajo iz Bruslja. Vendar na podlagi te ugotovitve $v 90$. letih ni prišlo z izjemo Velike Britanije - do vzpostavitve koherentne politike z jasno določenimi cilji in vidnimi uspehi (Radaelli, 2007). Pomemben mejnik na ravni Evropske unije predstavlja Mandelkernovo poročilo (2001), ki ga je pripravila skupina strokovnjakov po nalogu ministrov za javno upravo $v$ kontekstu uvajanja določil Lisbonske strategije o izboljšanju regulatornega okolja za podjetja (glej Radaelli in DeFrancesco, 2007). Bela knjiga o dobrem javnem upravljanju (White Paper on Good Governance, COM(2001)428 je istega leta posvetila posebno pozornost kakovosti regulacije in njen rezultat so bili nekateri konkretni predlogi - npr. predlog za sprejem minimalnih standardov posvetovanja z javnostjo in zaveza za pripravo akcijskega načrta za »boljšo regulacijo«. Leta 2002 je Komisija sprejela minimalne standarde za posvetovanje $\mathrm{z}$ javnostjo in pričela $\mathrm{s}$ sistematično uporabo presoje učinkov regulacije (kasneje, leta 2006, je bil za ta namen ustanovljen poseben odbor za presojo učinkov²).

Ideja, da je treba kakovost predpisov v številnih pogledih izboljšati oziroma sprožiti proces izboljšav, je $\vee$ Evropski uniji (in tudi $\vee$ Sloveniji) dozorela kot rezultat več procesov:

$1 \mathrm{~V}$ tem prispevku za izdajanje predpisov (oblastnih splošnih pravnih aktov, torej pravnih aktov, ki vsebujejo oblastne splošne pravne norme) uporabljamo izraz "regulacija", ki se je tudi sicer prijel v slovenski teoriji - glej monografijo Presoja učinkov regulacije $v$ Sloveniji (2009, urednica Polona Kovač).

2 Odbor je sestavljen iz visokih uradnikov direktoratov, ki so najbolj neposredno povezani s tremi stebri presoje učinkov predpisov (okolje, sociala, gospodarstvo) . 


\section{Gregor Virant}

- procesa priprave in uvajanja Lizbonske strategije za dvig konkurenčnosti evropskega gospodarstva ${ }^{3}$,

- procesa približevanja države in njenih institucij državljanom in

- procesa uvajanja upravljanja celovite kakovosti (total quality management).

a) Kakšna je zveza med izboljševanjem predpisov in izboljševanjem konkurenčnosti gospodarstva? Slabi predpisi, torej predpisi, ki so pripravljeni in sprejeti brez sodelovanja zainteresirane javnosti, brez realne ocene učinkov in brez čiščenja administrativnih ovir, povečujejo stroške poslovanja gospodarskih subjektov. Optimizacija predpisov za gospodarske subjekte pomeni optimizacijo regulatornega oziroma administrativnega okolja, v katerem poslujejo. Seveda je poleg kakovostnega procesa sprejemanja in kakovostne vsebine predpisov pomembno tudi učinkovito uvajanje. $\vee$ prvih letih je bil poudarek $v$ okviru projektov »boljše regulacije" predvsem na presoji učinkov regulacije in posvetovanju z zainteresirano in strokovno javnostjo. $\vee$ kasnejših letih, zlasti $\vee$ obdobju Barrosove komisije, pa je bilo vse bolj poudarjeno področje odprave administrativnih bremen (Meuwese, 2009, str. 97). Leta 2004 je Svet za konkurenčnost pozval Evropsko komisijo in države članice, naj ocenijo kumulativni učinek obstoječe zakonodaje na konkurenčnost industrije in specifičnih industrijskih sektorjev in naj razvijejo metodo za merjenje administrativnih bremen (Svet, 2004). Svet EU je marca leta 2007 sprejel sklep, da se morajo administrativna bremena, izhajajoča iz zakonodaje EU, do leta 2012 znižati za 25 odstotkov. Hkrati je povabil tudi države članice EU, da na nacionalni ravni postavijo »enako ambiciozne cilje».

b) Tudi zveza med izboljševanjem regulacije in približevanjem institucij države državljanom je na dlani. Regulacija je za državljane, ne proti njim. čeprav regulacija pomeni prisilno urejanje družbenih razmerij pod grožnjo sankcij, mora biti v službi državljanov. Zmanjševanje prepada med državo in državljani, tako imenovanega demokratičnega deficita, se $\vee$ veliki meri lahko ublaži prav $\mathrm{s}$ kakovostno politiko reguliranja - zlasti ko gre za pravila sodelovanja javnosti v procesih priprave in sprejemanja predpisov.

3 Evropska komisija je sprožila ambiciozen paket reform pod oznako "Better Regulation«, ki poteka od leta 2002. Gre za program poenostavitev zakonodaje, program za zmanjšanje administrativnih bremen za $25 \%$ do leta 2012 (sprejet leta 2005) in uporabo presoje učinkov regulacije (primarno na ravni Evropske komisije, z ambicijo, da se razširi tudi na Svet in na Evropski parlament) - glej Meuwese (2009), str. 93 do 96. 


\section{Gregor Virant \\ Izboljševanje kakovosti regulacije - razvoj v Sloveniji}

c) In kakšno povezavo ima proces uvajanja upravljanja celovite kakovosti z izboljševanjem predpisov? Ugotovili smo, da so predpisi eden najpomembnejših "produktov" javne uprave in je proces priprave in sprejemanja predpisov eden najpomembnejših procesov $v$ javni upravi. Glede na to je logično, da sta standardizacija in optimizacija tega procesa nujni sestavni del upravljanja celovite kakovosti v javni upravi. Vlada, ki želi uvajati kakovost v svoje poslovanje in $\vee$ poslovanje svojih ministrstev, mora razviti politiko kakovostne regulacije (regulatory policy), ki sledi načelom upravljanja kakovosti.

Uvajanje upravljanja celovite kakovosti je pomemben korak k izboljšavam v javni upravi. $\vee$ Sloveniji so organi javne uprave $\vee$ zgodnjih devetdesetih letih prejšnjega stoletja začeli z uvajanjem standardov ISO 9001, nadaljevali pa z uporabo ocenjevalnega orodja CAF (skupni ocenjevalni okvir za organizacije $v$ javnem sektorju) in $\mathrm{s}$ sodelovanjem $\mathrm{v}$ tekmovanju za priznanje Republike Slovenije za poslovno odličnost. $\vee$ te procese so se $-s$ podporo pristojnega ministrstva - vključevale skoraj izključno organizacije, ki predpise izvajajo (upravne enote, organi $v$ sestavi ministrstev), čeprav bi bilo izboljševanje kakovosti poslovanja na ravni ministrstev še kako pomembno. Uvajanje orodij upravljanja kakovosti bi povzročilo skrbnejši pristop k poslovnim procesom, tudi $k$ procesu priprave in sprejemanja predpisov. Seveda pa politike reguliranja ne more razviti vsako ministrstvo posebej, temveč mora biti to enotna vladna politika pod taktirko ministrstva, zadolženega za javno upravo. Razvoj politike reguliranja, ki smo mu priča $v$ zadnjih letih, se sicer ne odvija $\vee$ formalnih okvirih modelov upravljanja kakovosti, dejansko pa pomeni pomemben element upravljanja kakovosti. Lahko rečemo, da so spremembe na tem področju $v$ sozvočju z načeli upravljanja kakovosti in da brez upoštevanja teh načel spremembe ne bodo učinkovite. Gre za naslednja načela upravljanja kakovosti:

- $\quad$ procesi priprave in sprejemanja predpisov morajo biti skrbno standardizirani (seveda ob upoštevanju potrebne fleksibilnosti),

- vzpostavljena mora biti tesna vez z "odjemalci« (predvsem adresati predpisov, kot bomo videli kasneje, pa tudi izvajalci predpisov),

- $\vee$ politiko reguliranja mora biti vgrajen princip stalnih izboljšav (to politiko je treba sproti preverjati in po potrebi spreminjati),

- vodstvo ( $v$ tem primeru gre za predsednika vlade in ministre, za njimi pa vrhnji menedžment na ministrstvih) mora biti $s$ pomenom teh procesov seznanjeno in iskreno predano ciljem kakovosti ${ }^{4}$.

4 Glej načela upravljanja kakovosti po standardu ISO 9000 (www.iso.org). 


\section{Gregor Virant}

\section{Elementi kakovosti regulacije}

S povezavo med upravljanjem celovite kakovosti in izboljševanjem regulacije smo prišli do spoznanja, da je kakovost definirana z načeli (glej tudi Radaelli, DeFrancesco, str. 32). Mednarodne organizacije in nacionalne vlade so postavile vrsto načel dobre regulacije. Mandelkernovo poročilo (2002, str. 9 in 10) jih navaja sedem: nujnost, sorazmernost, subsidiarnost, transparentnost, odgovornost, dostopnost in enostavnost. Za primerjavo - slovenska Resolucija o normativni dejavnosti govori o načelu potrebnosti pravnega urejanja, samoomejevanju, sorazmernosti, odgovornosti, dostopnosti, poenostavitvah in transparentnosti. Primerjava pokaže, da gre praktično za isti seznam načel, le da je namesto načela subsidiarnosti (ki je izraz specifike Evropske unije kot nadnacionalne organizacije, čeprav je res, da se na ravni držav članic lahko uporablja za odnos med centralno vlado in lokalno samoupravo), uporablja pojem samoomejevanja, ki pa se $v$ veliki meri prekriva $z$ načelom potrebnosti pravnega urejanja.

Načela se konkretizirajo $v$ natančnejših standardih kakovosti regulacije, ki so zajeti $v$ regulatornih politikah Evropske unije in držav članic. Standardi kakovosti regulacije so določeni v različnih pravnih oblikah - praviloma gre za interno zavezujočo regulacijo organov Evropske unije (npr. smernice za presojo učinkov predpisov) in nacionalnih vlad, v številnih primerih pa tudi za »mehke« standarde, sprejete $\vee$ obliki priporočil, priročnikov ipd. Pravila, ki regulirajo regulacijo, avtorji pogosto označujejo kot metaregulacijo (Morgan, 2003, str. 57; Meuwese, 2008, str. 14).

Nabor standardov kakovosti regulacije je širok in odprt. Standardi se nanašajo predvsem na:
a) presojo učinkov regulacije,
b) sodelovanje zainteresirane javnosti,
C) odpravljanje administrativnih ovir,
d) (medresorsko) koherentnost,
e) tehnično (predvsem pravno in jezikovno) korektnost,
f) dostopnost predpisov (ustrezna objava) in
g) stalno evalvacijo kakovosti skozi izvajanje $v$ praksi ter proces izboljševanja.




\section{Gregor Virant \\ Izboljševanje kakovosti regulacije - razvoj v Sloveniji}

a) Presoja učinkov regulacije (regulatory impact assesment) pomeni, da morajo biti ob pripravi predpisa, ob njegovem obravnavanju in ob odločanju o njegovem sprejetju skrbno analizirani in prikazani njegovi učinki na javnofinančnem, makroekonomskem, mikroekonomskem, administrativnem, socialnem in okoljskem področju (presoja učinkov regulacije ali presoja učinkov vpliva na kakovost predpisa predvsem zato, ker odločevalcem daje jasno sliko o tem, kaj bo predpis $\vee$ praksi povzročil. Tako olajšuje izbiro med političnimi alternativami (zato je pogosto koristno, če je presoja opravljena za več variantnih odločitev). Skrbna presoja učinkov omogoča reguliranje družbenih razmerij po načelu odločanja na podlagi realnih dejstev ( $v$ nasprotju z odločanjem »na pamet", po intuiciji oziroma "na srečo«). Metode presoje učinkov se razvijajo z uporabo instrumentarija ekonomske, upravne, okoljske stroke in drugih strok.

Celovita in korektna presoja učinkov krepi tudi možnost kritike predpisov medijev, civilne družbe, opozicije itd., oziroma krepi moč institucij neformalnega in formalnega političnega nadzora. Izboljšuje tudi pogoje za sodelovanje javnosti $\vee$ procesih priprave in sprejemanja predpisa. Zainteresirana javnost namreč nima na voljo kadrovskih virov za izvajanje takšnih presoj, poleg tega pa lahko strokovno neoporečna, argumentirana in prepričljiva presoja vplivov odvrne kakšno kritiko in nasprotovanje, ki izhaja iz strahu ali nerazumevanja. Presoja učinkov regulacije na opisani način znatno pripomore k zmanjševanju demokratičnega deficita ter pozitivno vpliva na legitimnost regulacije.

b) $\vee$ pripravo in obravnavanje predpisa mora biti vključena zainteresirana javnost. Sodelovanje javnosti $\vee$ procesih priprave in sprejemanja predpisov (public consultation ali public participation) ${ }^{\mathbf{5}}$ ima večplasten pomen. Predvsem pozitivno vpliva na kakovost predpisa. Vključitev strokovne javnosti (strokovnjakov z univerze, raziskovalnih zavodov, iz gospodarstva...) in javnosti, na katero bo predpis vplival (t.i. zainteresirane javnosti) omogoči pripravljavcu boljši vpogled $v$ relevantne informacije o dejanskem stanju. Organizacije in posamezniki, ki so zainteresirani za vsebino predpisa, ker bo vplivala nanje, so pomemben vir informacij o dejanskem stanju ${ }^{6}$. Sodelovanje javnosti omogoči pripravljavcu tudi pravočasno zaznavanje potencialnih konfliktov in nasprotovanj in pretehtano odločanje o tem, ali koristi sporne odločitve odtehtajo negativne posledice konflikta. Konfliktnost interesov je seveda $v$ naravi političnega odločanja in redko

5 O stopnjah vpliva javnosti glej MJU (2008), str. 10. Priročnik loči naslednje stopnje (po naraščajočem vplivu): informiranje, posvetovanje, vključevanje, sodelovanje, pooblaščanje.

6 Seveda je treba biti pri uporabi teh informacij pozoren in previden, ker je lahko njihovo podajanje interesno pogojeno in posledično izkrivljeno. 
katera politična odločitev bo všeč vsem? mogoče izogniti brez stranskih posledic. Sodelovanje zainteresirane javnosti pomeni tudi ohranitev partnerskega odnosa med vlado in upravo na eni strani ter civilno družbo na drugi strani. To partnerstvo in medsebojno spoštovanje blagodejno vpliva tudi na izvajanje predpisa. Adresati predpisu priznavajo višjo stopnjo legitimnosti, če so lahko sodelovali pri njegovem nastajanju - tudi če jim ni uspelo uveljaviti vseh pripomb.

Sodelovanje javnosti pa ima seveda tudi velik pomen na področju demokratičnosti procesov javnega upravljanja, saj zmanjšuje tako imenovani demokratični deficit - pomanjkanje široke demokratične razprave ob sprejemanju političnih odločitev. Problem demokratičnega deficita je imanenten predstavniški demokraciji - državljani svojo politično odločitev izrečejo na volitvah, nato pa prepustijo odločanje o javnih zadevah svojim izvoljenim predstavnikom in imenovanim ministrom ter uradnikom. $\vee$ tem času jim je odločanje $\vee$ precejšnji meri odtujeno; ta pojav je neizogibna posledica narave predstavniške demokracije. Demokratični deficit je toliko bolj prisoten, kolikor bolj so institucije odločanja odmaknjene, oddaljene od državljanov - še posebej je torej prisoten pri sprejemanju podzakonskih predpisov, kjer razprava in odločanje ostaneta $v$ krogu izvršilne oblasti. Sodelovanje javnosti torej krepi demokratično naravo družbe.

c) $\vee$ procesu priprave je treba predpis "očistiti« vseh administrativnih ovir - bremen, ki ne prispevajo k cilju predpisa ali pa niso sorazmerna s tem ciljem. Predpisi, očiščeni administrativnih ovir, so za adresate racionalni, zato je večja tudi njihova legitimnost.

d) Element kakovosti predpisa je tudi njegova horizontalna medresorska usklajenost. Vladne politike morajo biti usklajene in koherentne. $V$ procesu medresorskega usklajevanja se predpis, ki sodi $v$ delovno področje enega od ministrstev, osvetli z vidika drugih resorjev. Predpis, ki je uravnotežen z vidika raznovrstnih javni interesov in ne zasleduje javnega interesa le na enem področju, pridobi na legitimnosti.

e) Novejša strokovna besedila s področja boljših predpisov redko omenjajo nekatere "trde" elemente kakovosti, ki so tradicionalno zasidrani v javnih upravah. Gre za nomotehnično kakovost, usklajenost s pravnim sistemom (s

7 Portugalski rek pravi, da ne moreš vladati tako, da bi bil vsem všeč. 


\section{Gregor Virant \\ Izboljševanje kakovosti regulacije - razvoj v Sloveniji}

prirejenimi in nadrejenimi predpisi) in jezikovno ter stilistično kakovost. Jezikovno ali nomotehnično pomanjkljiv predpis in predpis, ki na primer ni v skladu z ustavo ali direktivami EU, pač ni kakovosten predpis.

f) Za pravne subjekte je pomembna tudi dostopnost predpisa, torej možnost, da se lahko seznanijo z njegovo vsebino. Primerna metoda za doseganje tega standarda je brezplačna dostopnost na spletu. Pri tem je pomembno, da je objava pregledna - da so objavljena prečiščena besedila, da so spletne strani opremljene z uporabniku prijaznimi iskalniki, da so poleg zakonov objavljeni tudi podzakonski predpisi, izdani na njihovi podlagi, da so "pri roki« tudi pripadajoči interni akti z eksterno vsebino (navodila, okrožnice, pravna mnenja) in relevantna upravna in sodna praksa. Vse to namreč vpliva na interpretacijo in uvajanje predpisa in mora biti uporabniku dostopno, da bi se lahko $v$ celoti seznanil z vsebino predpisa in s svojim pravnim položajem.

g) Ob navedenih standardih kakovosti predpisov, ki so se uveljavili v teoretičnih pogledih na boljšo regulacijo in $v$ praksah nacionalnih javnih uprav, bi veljalo posebno pozornost posvetiti tudi sodelovanju izvajalcev predpisov. Pomembno vlogo pri pripravi predpisa bi morali vedno imeti tudi njegovi praktični izvajalci - torej strokovnjaki iz javne uprave, ki so oziroma bodo zadolženi za uporabo predpisa $\vee$ praksi (inšpektorji, uradne osebe upravnih enot, organov $v$ sestavi ministrstev, nosilcev javnih pooblastil, občinskih uprav). Ti strokovnjaki imajo najbolj neposredne in popolne informacije o učinkih določene regulacije, ki je že v veljavi, in tudi odličen vpogled v stanje "na terenu«, ki je zelo koristen pri presoji možnih učinkov nove regulacije. Z vključitvijo teh strokovnjakov $\checkmark$ pripravo predpisa lahko zagotovimo višjo kakovost pa tudi približamo predpis realnemu življenju in uporabnikom in na ta način zagotovimo višjo stopnjo kakovosti in legitimnosti predpisa. Smiselno bi bilo, da se standard "sodelovanja izvajalcev predpisa " vnese v nabor obveznih standardov v vseh aktih, ki te standarde predpisujejo ali priporočajo. 


\section{Izboljševanje kakovosti regulacije - razvoj v Sloveniji}

\section{Razvoj ideje o izboljševanju regulacije v Sloveniji}

V Sloveniji so nekateri tradicionalni elementi kakovosti regulacije vgrajeni v sistem priprave in sprejemanja predpisov vse od osamosvojitve naprej (izhajajoč iz tradicije izpred leta 1991): gre predvsem za presojo skladnosti s pravnim redom, nomotehnično korektnost, presojo javnofinančnih učinkov in medresorsko usklajenost (koherentnost). Nadzor nad nomotehnično in siceršnjo pravno korektnostjo je izvajala (in še izvaja) služba za zakonodajo, presojo finančnih posledic je vedno dosledno zahtevalo ministrstvo za finance, za medresorsko usklajenost pa je (poleg predlagateljev) skrbel in še skrbi generalni sekretariat. Ti elementi so bili ustrezno poudarjeni v vseh vladnih poslovnikih po osamosvojitvi. Druge, recimo jim modernejše, sestavine kakovosti regulacije pa so $v$ sistemsko ureditev in $v$ prakso prodirale počasi. Pomanjkljivo je bilo stanje na področju presoje učinkov (razen - kot že omenjeno - javnofinančnih), sodelovanja zainteresirane javnosti in odpravljanja administrativnih ovir. Prvi element boljše regulacije, ideja o poenostavljanju administrativnih postopkov, se je na vladni ravni pojavil leta $2000 \mathrm{~s}$ tako imenovanim "antibirokratskim programom«. Vendar poslovnik vlade ${ }^{8}$ iz leta 2001 ni vseboval določb, ki bi od predlagatelja gradiva zahtevale presojo učinkov, sodelovanje z javnostjo ali "čiščenje» administrativnih ovir. Izboljšave so prinesle spremembe in dopolnitve poslovnika vlade $\mathrm{v}$ letu $2006^{\mathbf{9}}$, ko je bil bistveno spremenjen in dopolnjen 8. člen. Tretji odstavek 8. člena poslovnika vlade je določil, da mora gradivo, poslano v vladno obravnavo, vsebovati "zagotovilo predlagatelja, da je opravil presojo učinkov predlaganih odločitev vlade in je izvedel potrebno medresorsko usklajevanje ter posvetovanje s predstavniki civilne družbe. Presoja učinkov se opravi na področju javnih finančnih sredstev, usklajenosti s pravnim redom Evropske unije, odprave administrativnih ovir in javne uprave, pravosodnih organov, gospodarstva, okolja in socialnega položaja posameznikov. Za pravilnost zagotovila odgovarja predlagatelj gradiva. Posamezna ministrstva in vladne službe morajo spremljati ustreznost tistega dela zagotovila, ki sodi $\vee$ njihovo pristojnost."

$\checkmark$ četrtem odstavku 8. člena pa je bilo določeno: „Jedro gradiva mora vsebovati obrazložitev predlaganih sklepov, ki vključuje tudi obrazložitev učinkov

8 Uradni list RS, št. 43/2001, 54/2003, 103/2003, 114/2004, 26/2006 in 21/2007

9 Uradni list RS, št. 26/2006 


\section{Gregor Virant}

\section{Izboljševanje kakovosti regulacije - razvoj v Sloveniji}

predlaganih ukrepov in druge podatke, potrebne za kakovostno odločanje vlade, ki jih določi generalni sekretar vlade. Če bo gradivo poslano v obravnavo državnemu zboru, mora vsebovati vse sestavine, ki jih predpisuje poslovnik državnega zbora."

S citiranimi poslovniškimi zahtevami so bili določeni »trdi« (zavezujoči) standardi kakovosti regulacije. Navedeni so bili vsi ključni elementi kakovosti (presoja učinkov, odprava administrativnih ovir, sodelovanje z zainteresirano javnostjo, medresorsko usklajevanje). Temu lahko dodamo še zahtevo po medresorskem usklajevanju (8.a člen poslovnika) in zahtevo, da mora predlagatelj predložiti gradivo "jezikovno in stilistično urejeno", kar je določal prvi odstavek istega člena poslovnika.

Podrobnejša navodila za predlagatelje gradiv je izdal generalni sekretar vlade. Navodila ${ }^{10}$ med drugim vsebujejo obrazec, ki določa obvezno vsebino izjav predlagateljev gradiv glede usklajenosti z nevladnimi organizacijami in glede odprave administrativnih ovir. V segmentu odprave administrativnih ovir je obrazec zahteven in podroben in terja od predlagatelja natančno analizo. Predlagatelj mora na primer navesti razloge, zakaj je postopek ali druga administrativna obveznost nujno potrebna, in javni interes, ki se s tem dosega. Navesti mora dokaze, da javnega interesa ni mogoče doseči na drug, za stranke enostavnejši način. Predlagatelj mora zagotoviti in opisati način izvajanja načela "vse na enem mestu" (načelo, da stranki ni treba opravljati zadev, ki se nanašajo na en življenjski oziroma poslovni dogodek, na več mestih). Navesti mora tudi podatke, potrebne za izvedbo postopka, ki jih bo pristojni organ pridobil sam iz uradnih evidenc, in način pridobivanja teh podatkov. $\vee$ segmentu sodelovanja javnosti na primer navodila določajo, da mora poročilo predlagatelja vsebovati izjavo, da je bilo gradivo predhodno objavljeno na spletni strani predlagatelja in so bile $v$ razpravo vključene nevladne organizacije oziroma predstavniki zainteresirane javnosti. Navesti je treba datum objave in seznam vključenih organizacij oziroma predstavnikov zainteresirane javnosti ter seznam tistih, ki so podali svoje mnenje. Poročati je treba tudi o tem, ali so bili prejeti pripombe in predlogi in ali so bili $v$ celoti upoštevani. če se z gradivom predlaga sprejetje predpisa, je treba negativne odgovore obrazložiti (ni pa $\vee$ navodilih določeno, kako).

S podrobnimi »izhodnimi« zahtevami glede odprave administrativnih ovir (zahtevami, ki se nanašajo na dokončno obliko gradiva, ki ga predlagatelj posreduje vladi) so bili predlagatelji $\vee$ tem segmentu usmerjeni $\vee$ pripravo kako-

10 Glej navodilo za izvajanje poslovnika vlade št. 10. 
vostnega gradiva. Poslovniški standard je nedvomno postopoma spreminjal tudi način razmišljanja oziroma pristop pri pripravi predpisov. Naj spomnimo, da je bilo določeno, da za posamezne elemente kakovosti primarno odgovarja predlagatelj, posamezna ministrstva in vladne službe pa morajo spremljati (torej nadzirati) ustreznost tistega dela zagotovila, ki sodi $\vee$ njihovo pristojnost - za odpravo administrativnih ovir in sodelovanje javnosti je zadolženo ministrstvo za javno upravo, za javnofinančne učinke ministrstvo za finance, za učinke na gospodarstvo ministrstvo za gospodarstvo itd. S spremembami in dopolnitvami poslovnika vlade $\vee$ letu 2006 so bili tako $\vee$ Sloveniji $\vee$ postopek vladnega odločanja vsaj na osnovni ravni ( $v$ nekaterih segmentih pa tudi na višji ravni) uvedeni standardi "boljše regulacije«. Znaten napredek na področju regulatornega upravljanja (regulatory management) $\vee$ Sloveniji je zaznala tudi SIGMA v svojem poročilu iz leta $2007^{11}$.

Junija 2008 je ministrstvo za javno upravo izdalo Priročnik za načrtovanje, vodenje in vrednotenje procesov sodelovanja javnosti. Priročnik vsebuje splošna pojasnila o pojmih in o pomenu vključevanja javnosti, pa tudi konkretna priporočila. Uporaba priročnika ni obvezna, dokument ima naravo delovnega pripomočka oziroma priporočil.

V letu 2009 je bil storjen nov korak na področju boljše regulacije. Državni zbor je sprejel »resolucijo o normativni dejavnosti« (Uradni list RS, št. 95/2009). Tako so bila načela dobre regulacije deklarativno postavljena na visoko politično raven, saj je resolucijo sprejel najvišji organ odločanja, zakonodajalec. Tako ima resolucija predvsem politični pomen, saj politično zavezuje vlado. Ne pa tudi pravno - nobenega predpisa ni mogoče izpodbijati pred ustavnim ali kakim drugim sodiščem zaradi neskladnosti z resolucijo. Prav tako resolucija nima operativne vrednosti; $v$ operativnem smislu imajo določbe poslovnika vlade večji pomen, saj neposredno usmerjajo pripravljavce oziroma predlagatelje gradiv za vladno obravnavo. Kljub temu velja sprejem resolucije kot političnega akta zakonodajnega telesa pozdraviti kot pomembno politično gesto.

Predlagatelj bi sicer lahko $v$ naslovu resolucije uporabil ustreznejši in modernejši, evropsko primerljiv termin (npr. resolucija o izboljševanju kakovosti regulacije ali resolucija o izboljševanju kakovosti predpisov), odločil pa se je za

11 SIGMA (2007), str. 15: There is a Programme of Measures for Reduction of Administrative Burdens which aims to reduce administrative barriers, ensure that public administration is friendly, effective, open and transparent, and provide impetus for the rapid development of e-government. All ministries are preparing work plans for the 2007-2008 period to reduce administrative burdens. The establishment in 2006 of a special group to oversee Better Regulation was a significant move towards the development of a comprehensive Better Regulation policy. 


\section{Gregor Virant \\ Izboljševanje kakovosti regulacije - razvoj v Sloveniji}

uporabo tradicionalne, pravne terminologije (»normativna dejavnost«). V resoluciji so določena načela oblikovanja in priprave predpisov: načelo potrebnosti pravnega urejanja, načelo samoomejevanja, načelo sorazmernosti, načelo odgovornosti, načelo dostopnosti, načelo poenostavitve in načelo transparentnosti $^{12}$.

$\mathrm{Na}$ področju presoje učinkov resolucija ne vsebuje konkretnih metodoloških orodij, temveč le splošen opis namena presoje, temeljne korake in splošna načela. Na področju sodelovanja javnosti je v resoluciji določenih nekaj »minimalnih priporočil«:

- $\quad$ sodelovanje javnosti pri pripravi predpisov naj traja praviloma od 30 do 60 dni; izjema so predlogi predpisov, pri katerih sodelovanje po naravi stvari ni mogoče (na primer: nujni postopki, državni proračun);

- pripravi naj se ustrezno gradivo, ki vsebuje povzetek vsebine s strokovnimi podlagami, ključna vprašanja in cilje;

- po končanem postopku sodelovanja naj se pripravi poročilo o sodelovanju s predstavitvijo vpliva na rešitve v predlogu predpisa;

- poziv k sodelovanju naj se izvede na način, ki bo zagotovil odziv ciljnih skupin in strokovnih javnosti ter obveščenost najširše javnosti.

V letu 2010 je bil ponovno spremenjen in dopolnjen poslovnik vlade, ki po novem ločeno obravnava standarde za zakone, podzakonske predpise in druge akte vlade. V novem 8.b členu je glede zakonov določeno, da »uvod predloga zakona vsebuje sestavine, določene s poslovnikom državnega zbora, in presojo posledic na posamezna področja ter povzetek o sodelovanju javnosti pri pripravi predloga zakona. Presoja posledic obsega vsaj:

- $\quad$ presojo finančnih posledic za državni proračun in druga javno finančna sredstva z načinom zagotovitve,

- presojo administrativnih posledic,

- $\quad$ presojo posledic na gospodarstvo, posebej na mala in srednja podjetja ter konkurenčnost podjetij,

12 Za primerjavo: v poročilu projektne skupine za boljše predpise (Task Force for Better Regulation) britanskemu predsedniku vlade o našteta naslednja načela kakovostne regulacije: sorazmernost, odgovornost, konsistentnost, transparentnost in ciljna usmerjenost. Zlasti slednje načelo pogrešamo $v$ naši resoluciji. Načelo ciljne usmerjenosti pomeni, da naj se predpis osredotoča na problem, ki ga je treba rešiti, in minimizira stranske učinke. Administrativne ovire so pogosto nastajale prav kot stranski učinki zasledovanja legitimnih javnih interesov zaradi nespoštovanja tega načela. 


\section{Gregor Virant}

- $\quad$ presojo posledic na okolje, ki vključuje tudi prostorske in varstvene vidike,

- $\quad$ presojo posledic na socialnem področju,

- $\quad$ presojo posledic glede na dokumente razvojnega načrtovanja.

Glede presoje posledic so izjema zakoni, ki se sprejemajo po nujnem postopku, in zakoni o ratifikaciji mednarodnih pogodb. Za zakone, sprejete po nujnem postopku, se o presoji posledic na posameznih področjih pripravi poročilo po dvoletnem izvajanju, ki se po obravnavi na vladi posreduje državnemu zboru $v$ vednost in objavi na spletnih straneh.

Glede podzakonskih predpisov poslovnik vlade v 8.c členu določa, da njihova obrazložitev vsebuje predstavitev pravne podlage, vsebinsko obrazložitev predlaganih rešitev in presojo posledic (analogno kot za zakon), vendar je presoja posledic potrebna le, če te niso mogle biti celovito predstavljene $\vee$ predlogu zakona (8.c).

Sodelovanje javnosti urejata 9. in 9.a člen poslovnika vlade. V 9. členu je določeno, da se predlogi in mnenja, ki jih strokovna in druga javnost naslavljata na vlado, pristojno ministrstvo ali vladno službo, proučijo in po možnosti upoštevajo ob naslednji pripravi predpisa. Ob pripravi predpisa mora predlagatelj povabiti strokovno in drugo javnost $\mathrm{k}$ sodelovanju pri pripravi predpisa $\mathrm{s}$ splošnim vabilom, kateremu je priložen osnutek predpisa, na spletnih stra$n^{n} h^{\mathbf{1 3}}$. Predlagatelj predpisa lahko tudi izpostavi posamezna vprašanja, ki jih z vabilom k sodelovanju, kateremu je priložen osnutek predpisa, naslovi na konkretno organizacijo, civilno-družbeno osebo ali posameznega strokovnjaka. Rok za odziv javnosti, ki ga določi predlagatelj, je 30 do 60 dni od objave na spletnih straneh oziroma $v$ skladu z dogovorom za sodelovanje po prejšnjem odstavku. Predlagatelj predpisa pisno seznani strokovno ali drugo javnost iz drugega odstavka tega člena o bistvenih predlogih ali mnenjih, ki niso bili upoštevani, z obrazložitvijo razlogov $\vee 15$ dneh od sprejema predpisa ali od posredovanja predloga predpisa $\vee$ nadaljnji postopek. Javnosti se ne povabi k sodelovanju pri

13 Gradivo, ki se objavi na spletnih straneh, vsebuje:

- osnutek predpisa,

- povzetek vsebine s strokovnimi podlagami, ključna vprašanja in cilje,

- čas trajanja javne predstavitve, $v$ katerem je mogoče posredovati stališča, predloge, mnenja in pripombe,

datum in kraj morebitne javne obravnave ali druge oblike sodelovanja in uradni elektronski naslov in telefon predlagatelja. 


\section{Gregor Virant \\ Izboljševanje kakovosti regulacije - razvoj v Sloveniji}

pripravi predlogov predpisov $v$ primerih, ko po naravi stvari to ni mogoče (ukrepi, ki se sprejemajo po nujnem postopku, ukrepi, ki morajo biti sprejeti in uveljavljeni nemudoma, z določenim začetkom veljavnosti brez predhodne seznanitve javnosti). Javnost se tudi ne povabi k sodelovanju pri pripravi predloga državnega proračuna, predloga rebalansa državnega proračuna, predloga sprememb državnega proračuna, predloga zakona o izvrševanju državnega proračuna in podzakonskih predpisov na njegovi podlagi, predloga zaključnega računa državnega proračuna, predloga poslovnika vlade, predloga odloka, predloga resolucije $z$ izjemo predloga resolucije o nacionalnem programu na posameznem področju, predloga dokumentov razvojnega načrtovanja in izvajanja razvojnih politik, predloga deklaracije, predloga aktov o ratifikaciji mednarodnih pogodb in predloga sklepa. Novo besedilo relevantnih določb poslovnika vlade ohranja in nadgrajuje standarde, ki jih je prinesla novelacija poslovnika vlade iz leta 2006. Na področju presoje učinkov bistvenih sprememb ni (le da so ločeno urejene sestavine predloga zakona, predloga podzakonskega predpisa in drugih gradiv, terminološko pa je "presojo učinkov" nadomestila "presoja posledic ${ }^{14}{ }^{4}$ ), na področju sodelovanja javnosti pa so pravila podrobnejša in bolj zavezujoča kot v starem besedilu.

Še en pomemben dokument, ki je trenutno $v$ fazi delovnega gradiva, je priročnik za izvajanje presoje posledic predpisov in politik, ki ga je pripravilo ministrstvo za javno upravo. Priročnik vsebuje dokaj podrobne standarde glede presoje učinkov (s pomožnimi vprašanji in navedbo mogočih področij, na katera regulacija vpliva), medresorskega usklajevanja in vključevanja javnosti v pripravo in sprejemanje predpisov ter drugih političnih aktov. Ministrstvo za javno upravo je pričelo tudi z usposabljanjem javnih uslužbencev na področju boljše regulacije, program usposabljanja je bil izveden trikrat - v marcu, aprilu in maju 2010.

Ugotovimo lahko, da slovenska državna uprava sledi razvoju na področju boljše regulacije. Od prvih zametkov sodobnih pristopov, ki so nastali na temelju tradicionalnih pogledov na postopek sprejemanja predpisov, je minilo približno deset let in $v$ tem času je prišlo do pospešenega razvoja modernejše »metaregulacije» (spremembe in dopolnitve poslovnika vlade leta 2006), do priprave »mehkih" standardov (t.i. soft law) v obliki priročnikov, sprejema parlamentarne resolucije in prvih kakovostnih programov usposabljanja.

Kje so še možnosti za izboljšave? Standardi, vsebovani v priročnikih, ki jih je pripravilo ministrstvo za javno upravo, bi morali postati zavezujoči za predlagatelje

14 To glede vsebine ne spremeni ničesar, je pa bil termin "učinki« bolj skladen z angleškim terminom "impact». 
gradiv. Vlada bi jih morala - morda nekoliko modificirane - sprejeti kot zavezujočo metodologijo ${ }^{15}$. Tako bi dobili zaokrožen sistem metaregulacije, ki bi (vsaj na normativni ravni) zagotavljala vse elemente kakovosti. Druga smer je krepitev zavesti in kompetenc, zlasti znanj s področja kakovostne regulacije. Postopno bi morali oblikovati kompetenčni profil delovnega mesta »regulatorja - pripravljavca predpisov. Predvsem pa je izjemnega pomena podpora vlade kot političnega vodstva državne uprave. Projekt izboljševanja predpisov lahko tako kot vsak drug projekt na področju upravljanja kakovosti uspe samo ob podpori najvišjega vodstva. $V$ primeru kakovosti regulacije gre seveda za vrh državne uprave na čelu s predsednikom vlade in ministri. Samo če bo kritično število članov vlade (predvsem pa predsednik vlade) razumelo prizadevanja za izboljšanje kakovosti predpisov in bodo politiki boljši regulaciji tudi iskreno predani, so lahko rezultati pozitivni. "Čuvaji« posameznih elementov kakovosti regulacije lahko do neke mere $z$ ustreznim ukrepanjem nevtralizirajo pomanjkljivosti $v$ resorjih, vendar to ni celovita in dokončna rešitev. Boljša regulacija mora postati filozofija celotne državne uprave in to je $v$ resnici mogoče le ob predanosti najvišjega vrha.

Treba je tudi dalje razvijati sistem nadzora nad upoštevanjem standardov kakovosti priprave in sprejemanja predpisov. Odgovornost za vse elemente kakovosti predpisa je $v$ prvi vrsti na predlagatelju. Ta mora $v$ celoti obvladovati proces priprave predpisa in si v primeru, da mu za posamezne elemente tega procesa manjka kadrovskih ali informacijskih virov, priskrbeti zunanjo pomoč. Na primer: izračun makroekonomskih učinkov predpisa lahko ministrstvo, ki ne razpolaga z ustreznimi znanji, prepusti vladnemu uradu za makroekonomske analize in razvoj. Za vsak element kakovosti predpisa je treba zagotoviti ustrezno strokovno pomoč in ustrezen nadzor usposobljene institucije. V državni upravi imamo institucije, ki so sposobne poskrbeti za ta nadzor. Nadzor nad področjem odprave administrativnih ovir in sodelovanjem javnosti naj še naprej izvaja ministrstvo za javno upravo, nadzor nad presojo makroekonomskih učinkov urad za makroekononske analize in razvoj, nadzor nad okoljskimi učinki ministrstvo za okolje, nadzor nad javnofinančnimi učinki ministrstvo za finance (ta nadzor ima $\vee$ naših vladnih postopkih, kot smo že omenili, močno tradicijo), nadzor nad nomotehnično korektnostjo služba za zakonodajo. Primarna odgovornost ostaja na predlagateljih, nadzorniki pa nosijo sekundarno odgovornost za kakovost predpisov. Končna (politična) odgovornost za kakovost predpisov pa je seveda na vladi. Glede nabora standardov kakovosti bi kazalo razmisliti o

15 Lahko bi ločili obvezni del, ki bi bil krajši in preciznejši, in priporočila oziroma priročnik. 


\section{Gregor Virant \\ Izboljševanje kakovosti regulacije - razvoj v Sloveniji}

obveznem vključevanju izvajalcev predpisov $v$ njegovo pripravo. Inšpektorji, uradniki upravnih enot in drugih organov, ki neposredno izvajajo predpise $v$ praksi, poznajo težave pri uvajanju in lahko izboljšajo presojo učinkov ter pripomorejo $k$ boljšim odločitvam. Poslovnik vlade bi tako lahko med obvezne sestavine predloga vnesel tudi izjavo o sodelovanju z izvajalci predpisa.

\section{Sklep}

Procesi izboljševanja kakovosti regulacije so se v Sloveniji po letu 2000 dobro razvijali. Največji napredek je pomenila sprememba 8. člena poslovnika vlade z zahtevo po presoji učinkov, ki vključuje tudi standard sodelovanja zainteresirane javnosti v procesu priprave in sprejemanja predpisov in "čiščenje» administrativnih ovir. Resolucija o normativni dejavnosti je na simbolni ravni dvignila področje boljše regulacije na višjo politično raven. Priročniki, ki jih je pripravilo ministrstvo za javno upravo, so kakovosten metodološki pripomoček, začeli pa so se tudi programi usposabljanja javnih uslužbencev. Obstaja pa še velik manevrski prostor za izboljšave: metodologija za sodelovanje javnosti in presojo učinkov bi morala postati zavezujoč vladni dokument. Izdelati bo treba tudi kompetenčni model za delovna mesta pripravljavcev predpisov in razviti ustrezen stalen program usposabljanja. Razmisliti velja tudi o razvoju novega standarda kakovosti regulacije, ki bi bil v evropskem merilu nekoliko inovativen: vključevanja izvajalcev predpisov $v$ njihovo pripravo in sprejemanje.

Dr. Gregor Virant se je po diplomi na Pravni fakulteti Univerze v Ljubljani zaposlil na Fakulteti za upravo kot asistent. Leta 1995 je na Pravni fakulteti zaključil magistrski študij, leta 1998 pa je doktoriral s področja pravnih znanosti (naslov disertacije: Razlastitev in omejitev lastninske pravice v javno korist). Od leta 1995 do 1999 je delal tudi kot svetovalec Ustavnega sodišča za področje referenduma, volitev in javne uprave. Od junija leta 2000 do avgusta 2004 je opravljal funkcijo državnega sekretarja na Ministrstvu za notranje zadeve. Leta 2004 je postal minister za javno upravo. V času svojega mandata je vodil temeljito modernizacijo javne uprave s poudarkom na poenostavljanju postopkov, izboljševanju kakovosti storitev za stranke in e-upravi. S podpisom kolektivnih pogodb je zaključil tudi šest let trajajočo reformo plačnega sistema v javnem sektorju. Od marca 2010 je zopet zaposlen na Fakulteti za upravo kot docent za področje upravnega prava in prava javne uprave. 


\section{Literatura in viri}

- Better Regulation Task Force Report to the Prime Minister (2005). Regulation - Less is more, Reducing Burdens, Improving Outcomes

- Bugarič, B. (2003). Odprta uprava in državljani: sodelovanje javnosti in analiza učinkov predpisov (RIA) v postopku sprejemanja predpisov. Zbornik IX. Dnevi javnega prava, Ljubljana: Inštitut za javno upravo pri Pravni fakulteti, str. 199-220.

- De Francesco, F.; Radaelli, C. (2007). Regulatory Quality in Europe - Concepts, Measures and Policy Processes, Manchester University Press.

- $\quad$ Frick, F., Ernst, T. (2008). International Regulatory Reform Report 2008, Bertelsmann Stiftung.

- Hampton, P. (2005). Reducing Administrative Burdens: Effective Inspection and Enforcement, HM Treasury.

- Jacobs, Scott et al. (1997). Regulatory Quality and Public Sector Reform, OECD Report on Regulatory Reform.

- Kirkpatrick, C.; Parker, D. et al. (2007). Regulatory Impact Assessment: Towards Better regulation?, Cheltenham: Edward Elgar Publishing.

- Kovač, P. (2009). Presoja učinkov regulacije - njeni elementi, cilji in pojavnost, monografija Presoja učinkov regulacije $v$ Sloveniji, Ljubljana: Fakulteta za upravo.

- Mandelkern Report on Better Regulation (2001).

- Meuwese, A. (2008). Impact Assessment in EU Lawmaking, Wolters Kluwer.

- Meuwese, A. (2009): Impact Assessment in the Multi-level Context of the European Union, monografija Presoja učinkov regulacije v Sloveniji, Ljubljana: Fakulteta za upravo.

- OECD (1997): Regulatory Impact Analysis - Best Practices in OECD Countries

- Peters, B.G.; Pierre, J. (2007). Handbook of Public Administration, London: Sage, New Delhi :Thousand Oaks.

- $\quad$ OECD (2000): Regulatory Reform in Denmark.

- $\quad$ OECD (2002): Regulatory Policies in OECD Countries, From Interventionism to Regulatory Governance.

- $\quad$ OECD (2005): Modernizing Government - The Way Forward.

- $\quad$ OECD (2007). Cutting Red Tape - Comparing Administrative Burdens across Countries.

- $\quad$ OECD (2007). Building A Framework For Conducting Regulatory Impact Analysis (RIA) Tools For Policy-Makers, Directorate for Public Governance and Territorial Development, Special Session of the OECD Working Party on Regulatory Management and Reform.

- $\quad$ Radaelli, C. (2007). Whither Better Regulation for the Lisbon Agenda?, Journal of European Public Policy, 14, str. 190-207 


\section{Gregor Virant \\ Izboljševanje kakovosti regulacije - razvoj v Sloveniji}

- Radaelli, C. M., De Francesco, F. (2007). Regulatory quality in Europe (Concepts, measures and policy processes). Manchester, New York: Manchester University Press...

- SIGMA (2007). Regulatory Management Capacities of Member States of the European Union that joined the Union on 1st May 2004.

- White Paper on Good Governnance, COM(2001)428.

- Zatler, Renata (2009). Odprava administrativnih ovir, XV. Dnevi javnega prava in javnega managementa, Portorož.

- Zatler, R., Čarni, M. (2009). Program boljšega reguliranja v Sloveniji in EU, monografija Presoja učinkov regulacije $v$ Sloveniji Ljubljana: Fakulteta za upravo.

- Poslovnik Vlade Republike Slovenije, Uradni list RS, št. 43/2001, 54/2003, 103/2003, $114 / 2004,26 / 2006$ in 21/2007 prečiščeno besedilo

- Resolucija državnega zbora Republike Slovenije o normativni dejavnosti (Uradni list RS, št. 95/2009).

- Navodila generalnega sekretarja Vlade Republike Slovenije za izvrševanje Poslovnika Vlade

- $\quad$ http://www.gsv.gov.si/fileadmin/gsv.gov.si/pageuploads/navodilo_st_03.doc 


\section{SUMMARY \\ IMPROVING THE QUALITY OF REGULATION - DEVELOPIMENT IN SLOVENIA}

The importance of the process of improving the quality of regulation has been gradually entering the "consciousness" of the EU institutions and national governments and public administrations. The idea of improving the quality of the regulation occurred on the agenda of the European Union and its Member States in the 90th years of the last century, when the Edinburgh Summit (1992) under the British Presidency expressed its concern over the quality and quantity of regulations coming from Brussels. However, on the basis of these findings in the 90th years - with the exception of the U.K. - a coherent policy with clearly defined goals and visible success has not been developed. An important milestone in the European Union was the Mandelkern Report (2001), prepared by the Expert Group in the context of the implementation of the Lisbon Strategy with the aim to improve the regulatory environment for business. The same year, the White Paper on Good Governance (COM 2001, 428) paid particular attention to the quality of regulation and its results have been some concrete proposals - a proposal to adopt minimum standards of public consultation and a commitment to prepare an action plan for "better regulation". In 2002 the Commission adopted minimum standards for consultation with the public and began the systematic use of regulatory impact assessments.

The idea that a process of improvements has to be initiated in the field of regulation has developed in EU and also in Slovenia as a result of several processes:

a) the process of preparation and implementation of the Lisbon strategy to increase competitiveness of the European economies,

b) the process of orienting the state and its institutions towards the citizens, and

c) the process of introducing total quality management (TOM).

Quality of regulation is defined by principles. International organizations and national governments have set a series of principles of good regulation. Mandelkern report (2002, p. 9 and 10) defines seven principles of good 
Gregor Virant

Izboljševanje kakovosti regulacije - razvoj v Sloveniji

regulation: necessity, proportionality, subsidiarity, transparency, accountability, accessibility and simplicity.

The principles are concretised by quality standards which are included in the regulatory policies of the European Union and the Member States. Quality standards are set out in various legal forms - as binding internal rules of the EU institutions (e.g. guidelines for assessing the impact of regulations) and national governments, or as "soft" standards adopted in the form of recommendations, manuals, etc. . The rules governing regulation are often referred to as meta-regulation.

A set of quality standards and regulation is wide open. The standards are based primarily on:

a) assessing the impact of regulation,

b) participation of the interested public,

c) elimination of administrative barriers,

d) (interdepartmental) coordination and coherence,

e) technical (primarily legal and linguistic) correctness

f) accessibility of regulations (appropriate publication) and

g) continuous (ex post) evaluation of impact.

In Slovenia, some traditional elements of the quality of regulation had been built into the system of drafting and adopting regulations even before gaining independence (derived from the tradition of pre-1991): control of accordance with the legal order, nomotechnical correctness, the assessment of financial impact and inter-ministerial coordination (coherence). These elements have been appropriately highlighted in the Rules of Procedure of the Government.

The "modern " components of the quality of regulation penetrated into practice quite slowly. The main deficiencies were in the areas of regulatory impact assessment (except for financial impact), public participation and removal of administrative burden. The first element of better regulation, the idea of simplifying administrative procedures, appeared at the governmental level in $\mathbf{2 0 0 0}$ with the so-called "anti-bureaucratic program." However, the Rules of Procedure of the Government from 2001 did not contain provisions that would require a thorough impact assessment, public participation or removal of administrative burden. 
Improvements were introduced with amendments to the Rules of Procedure of the Government in 2006. The Rules have determined that the material sent to a government procedure, shall include "a statement of the proposing ministry that an impact assessment of the proposed decision and the necessary inter-ministerial coordination and consultation with representatives of civil society had been made."

In 2009 a new step in the field of better regulation was made. The National Assembly adopted a "Resolution of the rule-making activity" (Official Gazette, No. 95/2009). Thus, the principles of good regulation were declaratively confirmed on the highest political level. The resolution doesn't bring any legal obligations, but is politicaly binding for the Government.

The Resolution also has no practical or operational value - in this sense, the Rules of Procedure of the Government have greater importance because they bring concrete operative rules for preparation of the proposals to the Government. However, the adoption of the Resolution was an important political gesture.

In 2010 the Rules of Procedure of the Government were amended again. The new wording of the relevant provisions of the Rules of Procedure of the Government maintains and upgrades the standards brought by the 2006 amendments. Regarding the impact assessment no significant changes were made. On the other hand, in the field of public participation the rules are more detailed and more prescriptive than the old text.

Another important document that is currently under preparation is the Manual for the implementation of impact assessment of regulations and policies, prepared by the Ministry of Public Administration. The draft Manual contains fairly detailed standards for the assessment of the impacts (with auxiliary questions and an indication of possible areas in which the regulation could have impact), inter-ministerial coordination and public participation in the preparation and adoption of regulations and other political acts. Ministry of Public Administration has also begun the training of public servants in the field of better regulation.

We can conclude that the Slovenian Public Administration is following the developments in the field of better regulation. We have been witnessing a development of modern "meta-regulation" (amendments to the Rules of Procedure of the Government). Soft standards in the form of manuals were also prepared and a parliamentary Resolution was adopted. 
Gregor Virant

Izboljševanje kakovosti regulacije - razvoj v Sloveniji

Significant progress in regulatory governance (Regulatory Management) in Slovenia was recognised by the SIGMA report in 2007.

But there is still place for improvements The standards contained in the "soft law" (manuals prepared by the Ministry of Public Administration) should become binding for the ministries. The Government should accept them - perhaps in a slightly modified version - as a binding methodology. This would lead to a unified system of meta-regulation that would (at least at the regulatory level) provide all the elements of quality.

The system of ensuring compliance with quality standards should also be further developed. Responsibility for all elements of quality regulation is primarily on the proposing authority. The proposing ministry should fully manage the process of preparing new regulations, and in case of lack of human resources or information aid from outside should be provided. For example: to calculate the macroeconomic effects of regulation, the Ministry may not have the relevant skills, so this excersise can be left to the Government Office of Macroeconomic Analysis and Development.

Regarding the set of quality standards, it would be useful to consider the compulsory involvement of those civil servants who are responsible for the implementation of the regulation. Inspectors, officials of administrative units and other agencies directly implementing the rules in practice, familiar with the problems of the implementation and with the impacts of the regulation in practice, can contribute to better decisions.

There is also a need to raise awareness and skills, particularly in the field of quality control. The Government should gradually develop a competency profile for the posts of civil servants responsible for the preparation of regulations. A culture of better regulation is necessary. "Watchdogs" of individual elements of the quality of regulation can to some extent neutralize defficiencies in departments, but this is not a complete and definitive solution. Better regulation must become a philosophy of the whole public administration.

And above all, political leadership and support is needed. The project of improving the quality of regulation, like any other project in the field of quality management, can only be successful if there is support from the leadership of the organization. Only if a critical number of members of the Government (particularly the Prime Minister) understand the importance of improving the quality of regulation and are sincerely committed to better regulation, the results may be positive. 